\title{
Examining the Safety of Duck Breast Prepared the Sous Vide Method Sara Plain ${ }^{1}$, Helen Heacock ${ }^{2}$, Lorraine McIntyre ${ }^{3}$
}

1 Lead Author, School of Health Sciences, British Columbia Institute of Technology, Burnaby, BC 2 Supervisor, School of Health Sciences, British Columbia Institute of Technology, Burnaby, BC

3 Contributor, British Columbia Centre of Disease Control, 655 West 12th Ave, Vancouver, BC

\begin{abstract}
Objectives: There is an increasing desire in the culinary industry to use sous vide to prepare meals at low internal temperatures to enhance flavour, texture, and quality. The sous vide method uses specific time and temperature combinations to allow for sufficient microbial destruction. The BCCDC's Guidelines for Restaurant Sous Vide Cooking Safety in British Columbia suggests time and temperature combinations to help ensure that the required $\log _{10}$ reductions of pathogens are achieved. Concerns for public safety arise when chefs deviate from the guidelines, and therefore may not achieve the appropriate $\log _{10}$ reductions. This study looked at a commonly used sous vide duck breast recipe and determine whether appropriate the appropriate $\log _{10}$ reductions were met. It also examine the efficacy of the sear step and resting period in achieving the $\log _{10}$ reductions.
\end{abstract}

Methods: After calibration, two batches of 15 duck breasts were prepared using the sous vide method for 80 minutes at $58^{\circ} \mathrm{C}$, the breasts were then seared on a $200^{\circ} \mathrm{C}$ frying pan for 2 minutes each side, and then subjected to a 4 minute rest period at room temperature. The internal temperature of the breasts was continuously measured using SmartButton thermometers. This data was entered into the AMI Process Lethality Determination Spreadsheet to calculate the $\log _{10}$ reductions. The $\log _{10}$ reductions were analyzed using a one-sample t-test to assess whether the recipe achieved the required $7.0 \log _{10}$ reductions.

Results: The results showed $14 \%$ of the 29 duck breasts achieved a $7.0 \log _{10}$ reduction after the sous vide step of 80 minutes at $58{ }^{\circ} \mathrm{C}$. The null hypothesis $\left(\mathrm{H}_{0}\right.$ : measured $\log _{10}$ reductions of duck breasts $=7.0 \log _{10}$ reductions) was rejected with $100 \%$ power and a p-value of 0.00 . The mean was 5.13 , therefore it seems as though the $\log _{10}$ reductions were significantly lower than $7.0 \log _{10}$ reductions. After the sear and the resting period, $52 \%$ of 27 duck breasts achieved a $7.0 \log _{10}$ reduction. Statistical analyses showed that the null hypothesis could not be rejected. The p-value was 0.97 and the power was 0.413 . Disregarding cumulative effects, the median $\log _{10}$ reductions achieved only by the sear step was 0.43 , and the median $\log _{10}$ reductions achieved solely by the resting period was 0.35 .

Conclusion: Due to lack of normality one cannot confidently say this recipe will achieve $7.0 \log _{10}$ reductions. However, due to the high $\log _{10}$ reductions achieved, it seems plausible for another recipe to provide adequate $\log _{10}$ reductions while maintaining acceptable quality. The sous vide step should be used for the majority of the $\log _{10}$ reductions. Due to a wide variability in the results, the sear and resting period should only be used for small increases in $\log _{10}$ reductions.

Keywords: Sous vide, duck breast, temperature, SmartButton, public health, sear, foodborne illness

\section{INTRODUCTION}

Concerns have been raised by the British Columbia Center for Disease Control (BCCDC) regarding the safety of sous vide duck breast served with the center still pink (1). In 2015, the BCCDC received one reported case of Salmonella illness that was potentially linked to sous vide duck breast, and another incident of Salmonella illness that arose from grilled duck breast prepared at $58^{\circ} \mathrm{C}$ (1). After these two illnesses were reported, Lorraine McIntyre from the BCCDC determined that more research 
needed regarding the safety of sous vide duck breast.

The public health concern is that many chefs believe that duck breast can be cooked at lower times and temperatures than recommended to achieve a desired pink colour in the meat. According to several blog sites, many chefs believe that the hot paraffin wax used to defeather the ducks kills the bacteria Salmonella, and therefore makes the duck meat safe to eat served pink (1). The chefs also claim that unlike chicken, duck breasts are not injected for moisture; therefore Salmonella will not be forced into the meat from the exterior (1). However, a meat safety specialist interviewed by the BCCDC stated that the wax does not get hot enough to kill the bacteria; the wax only reaches between $57^{\circ} \mathrm{C}$ to $71^{\circ} \mathrm{C}$, and lower temperatures may also be used $(1,2)$. These temperatures do not meet the necessary temperatures for microbial destruction. For adequate microbial destruction Health Canada recommends that all poultry must be cooked to an internal temperature of $82^{\circ} \mathrm{C}$, and the Food Retail and Food Service Code recommends a temperatures of $85^{\circ} \mathrm{C}(3,4)$. The minimum temperature requirement for poultry is $74^{\circ} \mathrm{C}$; this temperature is recommended by the Canadian Government, the BCCDC, and the Food and Drug Administration (FDA) $(1,5,6)$. The purpose of this report is to examine if a common sous vide duck recipe with a final sear and rest achieves adequate microbial destruction.

\section{LITERATURE REVIEW}

Pathogens Associated with Duck Meat Along with Salmonella there are other common pathogens associated with duck meat including Listeria, Yersina, Campylobacter and the Avian Flu $(1,7,8)$. In fact, studies have shown that Campylobacter has a $32 \%$ prevalence in the meat, and Salmonella has a $28 \%$ prevalence in duck meat and parts (1). There is also current evidence that suggests that Campylobacter infections in humans are related to duck meat. A study of campylobacteriosis outbreaks in the United Kingdom found that duck meat was the source of $2 \%$ of the outbreaks (8). Considering the prevalence of Campylobacter in the meat, and the documented outbreaks in the United Kingdom, it is reasonable to assume that duck meat may be an underestimated contributor to camplyobateriosis cases (8). Due to these potential pathogens it is necessary to ensure microbial destruction.

\section{Sous Vide}

To eliminate these pathogens and retain the pink colour in meat, chefs have begun using the sous vide method. Sous vide is "defined as the cooking of raw materials under controlled conditions of temperature and time, inside heat-stable vacuumized pouches or containers followed by rapid cooling" (9, p572). It is a type of low-temperature longtime method of cooking that has existed in restaurants since the 1970s and has become increasingly popular since the early-2000s $(10,11)$. The sous vide method often uses low temperatures below $70^{\circ} \mathrm{C}$ to cook fish and meat (12). These low temperatures can be used safely if coupled with a long enough cook time to adequately destroy pathogens; the cook times used may range from minutes to days depending on the temperature (13). It is essential for safety to ensure that proper time and temperature combinations are used.

\section{Safety of Sous Vide}

To ensure the safety of poultry the Canadian Food Inspection Agency (CFIA) requires 7.0 $\log _{10}$ reductions in Salmonella spp. (14). A $\log _{10}$ reductions, or logarithm, means to reduce the pathogens "by a factor of ten" $(11, \mathrm{p} 2)$. If the adequate $\log _{10}$ reductions are achieved then the process is referred to as "sous vide pasteurization (SVP)" and the food is considered safe for consumption (11, 
p3). If $7.0 \log _{10}$ reductions are not achieved for poultry, the food is considered raw and must be processed longer to achieve the proper $\log _{10}$ reductions, or cooked to an internal temperature of $74^{\circ} \mathrm{C}(11)$.

Globally there are criteria for sous vide in the U.S. Food and Drug Administration's Food Code, as well as guidelines available in Australia (11). In Canada, the only guidelines for sous vide are the BCCDC's Guidelines for Restaurant Sous Vide Cooking Safety in British Columbia (11). These guidelines are consistent with the other guidelines and supported by microbiological studies done by the University of Wisconsin-Madison and HansonTech $(15,16,17,11,18)$. Chefs are recommended to follow these guidelines to ensure proper microbial destruction.

Unfortunately, sous vide might not destroy spore forming bacteria, such as Clostridium botulinum; this pathogen can survive in the oxygen free environment provided by vacuum packaging (19). To limit the growth of C.botulinum sous vide products should be stored at $\leq 3.3^{\circ} \mathrm{C}$ for $\leq 7$ days (11). Proper storage is therefore also essential for safety.

\section{Potentially Problematic Recipes} Issues regarding safety may arrive when chefs deviate from the guidelines. For example, a study done by Nova Do examined a sous vide chicken recipe and found did not match the guidelines nor did it achieve sous vide pasteurization (20). In addition, Rebecca Li examined the safety of sous vide salmon and also showed that the recipe also did not meet the guidelines nor did it achieve sous vide pasteurization (21). Both of these studies suggested that recipes that do not meet the guidelines may not achieve appropriate internal temperatures.

Alternatives to the Guidelines
Recipes that do not meet guidelines may still be acceptable if they can prove that they met the acceptable $\log _{10}$ reductions.

This can be done by first determining the DValue, T-ref, and z-value for the pathogen of concern, and then measuring the internal temperature of the dish. Calculations to determine the $\log _{10}$ reductions can be easily done by using the AMI Process Lethality Determination Spreadsheet provided by the North American Meat Institute (22).

\section{Searing}

If sous vide pasteurization is not achieved, many chefs claim that a sear step at $200^{\circ} \mathrm{C}$ to $250^{\circ} \mathrm{C}$ for short periods of time will help achieve adequate internal temperatures (10). However, more research is needed to assess the searing step as a critical control.

\section{PURPOSE}

Recent outbreaks, and studies regarding the microbial composition of duck meat have prompted concerns with the efficacy of common sous vide duck breast recipes (1). In addition, there are current questions regarding the efficacy of the sear step. Previous studies by Do, and Li examined the efficacy of the sear step. Do's study only examined the sear of one sous vide chicken breast and concluded that the sear did help it achieve sous vide pasteurization (20). Li's study examined 30 sous vides salmon samples that were seared and concluded that the sear step did not help it achieve sous vide pasteurization. Therefore, this experiment was designed to examine whether sous vide duck recipes that do not meet BCCDC's guidelines can achieve adequate $\log _{10}$ reductions. In addition this experiment examined if there are significant increases in $\log _{10}$ reductions during the sear step and resting period. Lastly, this experiment used a rough qualitative analysis to assess the recipe's practicality. 


\section{METHODS}

The following describes the methods used to conduct the experiment.

ACR SmartButton Data Loggers: The SmartButtons (SmartButton, ACR, Surrey, British Columbia) were prepared by installing the TrendReader ${ }^{\circledR}$ software onto a PC computer and then individually programming each button to 1 minute data collection intervals and the memory usage to stop when full. The start time was programmed to begin immediately.

Immersion Circulators: Immersion Circulators (Sous Vide Professional, PolyScience, Torrance, California) were set to $58^{\circ} \mathrm{C}$ and calibrated using a calibrated lollipop thermometer (Waterproof Lollipop Min/Max Thermometer, DeltaTrak, Pleasanton, California). No adjustments were needed; the immersion circulation was accurate within $\pm 0.05^{\circ} \mathrm{C}$.

Duck Breast Preparation: Each breast was weighed and trimmed to approximately $188 \mathrm{~g}$. Next the fat on each breast was scored and the breasts were formed to ensure uniform thickness and shape using cellophane; each breast was roughly $32 \mathrm{~mm}$ thick. Next, an ACR SmartButton thermometer was inserted into in the thickest part of each breast. The breasts were placed in separate food grade bags and vacuum packaged using a Vacuum Sealer (Komet PlusVac 25, Plochingen, Germany), labeled, and then placed into a cooler.

Sous Vide: Once the immersion circulators reached $58^{\circ} \mathrm{C}, 7$ to 8 sealed breasts were placed in each bath to make a total batch of 15 , as seen in Figure 1. The breasts were completely immersed in the $58^{\circ} \mathrm{C}$ water and a timer was set for 80 minutes. Once the 80 minutes was complete, all of the breasts were removed from the water bath at once, their vacuum packages were opened, and the time was recorded.

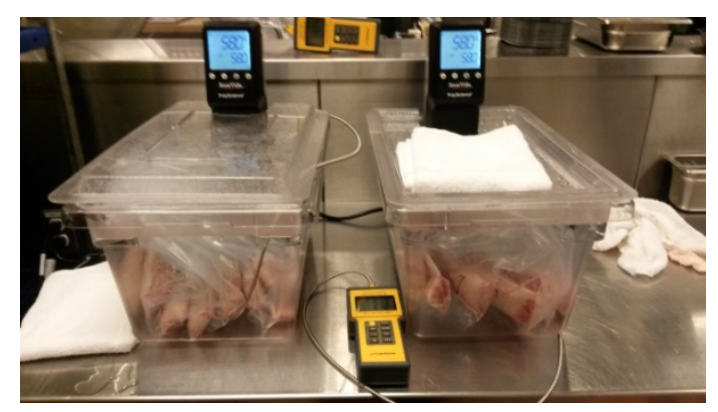

Figure 1: Sous Vide Water Bath

\section{Searing and Resting} Step: A frying pan was heated to approximately $200^{\circ} \mathrm{C}$, the temperature was measured using an infrared thermometer (Infrared and Contact Thermometers, Fluke, Mississauga, Ontario). Three student chefs

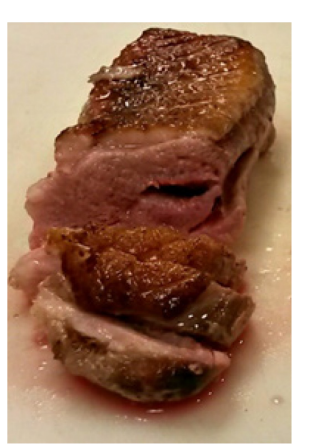

Figure 2: Sous Vide Duck helped sear six breasts at Breast after Sear and Rest
a time. The other breasts remained at room temperature while waiting to be seared. The duck breasts were placed on the $200^{\circ} \mathrm{C}$ pan for 2 minutes on each side while being basted with a spoon. Once finished the breasts were then removed and rested for 4 minutes. After resting, the SmartButton thermometers were removed and connected to a PC using a USB interface cable to retrieve the data. The temperature readings were converted into $\log _{10}$ reductions and statistically analyzed. In addition, Chef Laura rated each breast based on taste and texture, a picture of the finished breast can be seen in Figure 2.

Batch Two: The next batch of 15 was completed following the same procedure. The variance was that an ice bath was used for cooling. In addition, only four breasts were seared at once, as opposed to six. 


\section{STATISTICAL ANALYSIS \& RESULTS}

Although 30 samples were used, only 29 thermometers successfully recorded the data. In addition, two thermometers contacted the pan during the sear step and were ruled out as outliers.

\section{Descriptive Statistics}

Below are the descriptive statistics results:

Table 1: Sous Vide Process

\begin{tabular}{|l|l|}
\hline Mean & $5.13 \log _{10}$ reductions \\
\hline Median & 4.99 $\log _{10}$ reductions \\
\hline Standard Deviation & $0.28 \log _{10}$ reductions \\
\hline Mode & $4.77 \log _{10}$ reductions \\
\hline
\end{tabular}

Table 2: Sear Step

\begin{tabular}{|l|l|}
\hline Mean & $8.13 \log _{10}$ reductions \\
\hline Median & $6.77 \log _{10}$ reductions \\
\hline Standard Deviation & $0.92 \log _{10}$ reductions \\
\hline Mode & $6.13 \log _{10}$ reductions \\
\hline
\end{tabular}

Table 3: Rest Period

\begin{tabular}{|l|l|}
\hline Mean & $\begin{array}{l}15.53 \log _{10} \\
\text { reductions }\end{array}$ \\
\hline Median & $7.08 \log _{10}$ reductions \\
\hline Standard Deviation & $4.42 \log _{10}$ reductions \\
\hline Mode & N/A $\log _{10}$ reductions \\
\hline
\end{tabular}

assessed to give a better indication of the efficacy of the sear and rest step.

As seen in Figure 3, the sear and rest step achieved a wide variety of $\log _{10}$ reductions. In general, they only achieved small $\log _{10}$ reductions. The median $\log _{10}$ reductions caused by the sear step was 0.43 , and the median $\log _{10}$ reductions caused by the rest period was 0.35 (24).

\section{Qualitative Analysis}

To assess the general practicality of the recipe, Chef Laura Dawe rated the texture and taste of each duck breast on a scale of 15 , where 1 was the lowest quality and 5 was the highest (24). The mean rating for colour was 4.3 , and the mean rating for texture was 4.4 (24).

\section{Statistics}

The Null and Alternative Hypotheses examined are as follows:

\section{Sous Vide Process}

$\mathbf{H}_{\mathbf{0}}: \mu \log _{10}$ reductions of Salmonella spp. in the duck breasts cooked at $58^{\circ} \mathrm{C}$ for $80 \mathrm{~min}$ $=7.0 \log _{10}$ reductions in Salmonella spp.

Ha: $\mu \log _{10}$ reductions of Salmonella spp. in the duck breasts cooked at $58^{\circ} \mathrm{C}$ for $80 \mathrm{~min}$ $\neq 7.0 \log _{10}$ reductions in Salmonella spp.

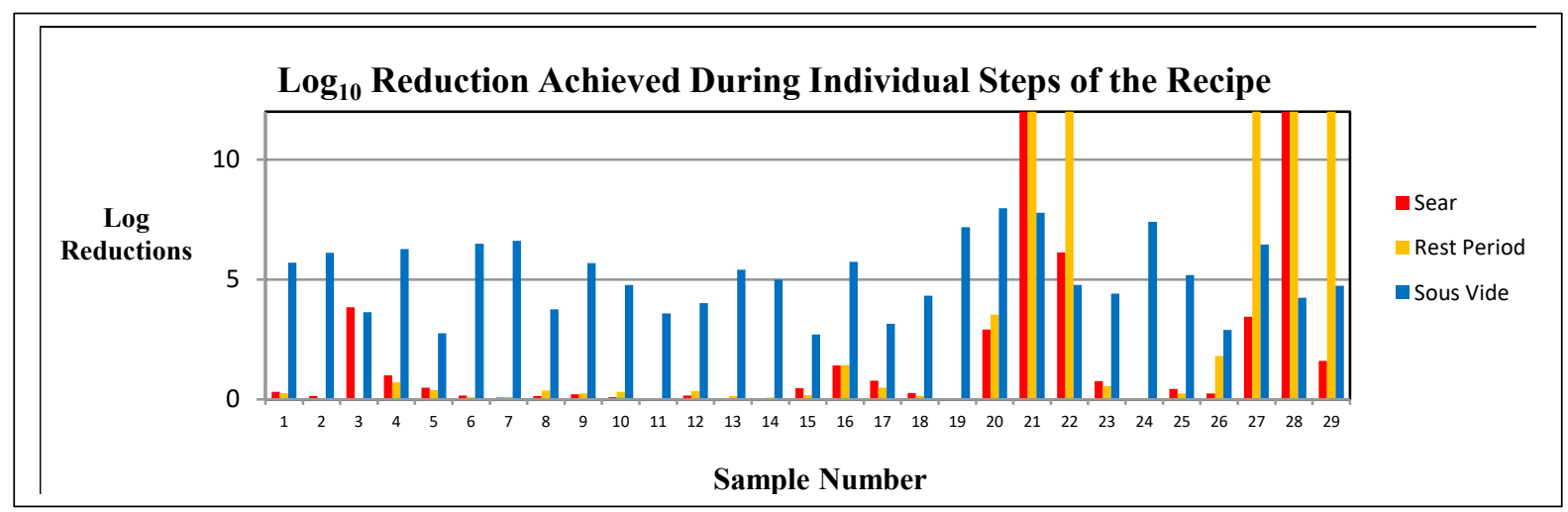

Figure 3: $\log _{10}$ Reductions Achieved During Individual Steps of the Recipe

Tables $1,2,3$ show the cumulative $\log _{10}$ reductions achieved after each step. However, the steps were also individually

\section{Sear Step}

$\mathbf{H}_{0}: \mu \log _{10}$ reductions of Salmonella spp. in the duck breasts cooked at $58^{\circ} \mathrm{C}$ for $80 \mathrm{~min}$ 
with a sear of $200^{\circ} \mathrm{C}$ for $4 \mathrm{~min}=7.0 \log _{10}$ reductions in Salmonella spp.

$\mathbf{H}_{\mathbf{a}} \boldsymbol{\mu} \log _{10}$ reductions of Salmonella spp. in the duck breasts cooked at $58^{\circ} \mathrm{C}$ for $80 \mathrm{~min}$ with a sear of $200^{\circ} \mathrm{C}$ for $4 \mathrm{~min} \neq 7.0 \log _{10}$ reductions in Salmonella spp.

\section{Rest Period}

$\mathbf{H}_{\mathbf{0}}: \mu \log _{10}$ reductions of Salmonella spp. in the duck breasts cooked at $58^{\circ} \mathrm{C}$ for $80 \mathrm{~min}$ with a sear of $200^{\circ} \mathrm{C}$ for 4 min with a 4 min rest $=7.0 \log _{10}$ reductions in Salmonella spp.

$\mathbf{H}_{\mathbf{a}}: \mu \log _{10}$ reductions of Salmonella spp. in the duck breasts cooked at $58^{\circ} \mathrm{C}$ for $80 \mathrm{~min}$ with a sear of $200^{\circ} \mathrm{C}$ for 4 min with a $4 \mathrm{~min}$ rest $\neq 7.0 \log _{10}$ reductions in Salmonella spp.

\section{Interpretation of the Data}

A one tailed t-test was used to compare the samples in each step to the $7.0 \log _{10}$ reductions required by the CFIA for sous vide poultry using NCSS 9 and Microsoft Excel 2010(23).

Sous Vide Process: The data was normally distributed; hence, a parametric one-sample $\mathrm{t}$-test was used (23). The p-value was 0.00 which is significantly less than 0.05 ; therefore, the null hypothesis was rejected and it was concluded that the mean $\log _{10}$ reductions achieved for the duck breasts was statistically significantly different than the required $7.0 \log _{10}$ reductions (23). Based on the fact that the mean was $5.13 \log _{10}$ reductions, it seems that the $\log _{10}$ reductions were significantly lower than $7.0 \log _{10}$ reductions. The power for the parametric test was 1.00 showing that there is a high probability of correctly concluding to reject the null hypothesis (23).

Sear Step: The data was not normally distributed; hence, the Wilcoxon Signed Rank Test was used (23). The p-value was 0.96 . Therefore, the null hypothesis was not rejected and it was concluded that the mean $\log _{10}$ reductions achieved was not statistically significantly different than 7.0 $\log _{10}$ reductions (23). The power for the parametric test was 0.22 .

Rest Period: The data was not normally distributed and the Wilcoxon Signed Rank Test was used (23). The p-value was 0.40 . Therefore the null hypothesis was not rejected and it was concluded that the mean $\log _{10}$ reductions was not statistically significantly different than $7.0 \log _{10}$ reductions (23). The power for the parametric test was 0.41 .

\section{LIMITATIONS}

Sample Size: Due to time constraints, only 30 duck breasts were tested. One of the thermometers failed, leaving only 29 duck breasts. In addition, two samples were removed as outliers because the thermometers became exposed to the frying pan.

Difference in Sample 1: The first breast was tested with different parameters. The recipe was changed to be more practical. Sample 1 had a $57^{\circ} \mathrm{C}$ sous vide step for 80 minutes, a 2 minute sear, and a 5 minute rest.

\section{Difference in Time from Sous Vide to}

Sear: Due to a lack of chefs and frying pans, the breasts had to wait to be seared. The wait times varied between 5 minutes to 30 minutes. Although these wait times were not a part of the recipe, a mean $1.22 \log _{10}$ reductions was achieved during this time.

Positioning in the Water Bath: The $\log _{10}$ reductions achieved during the sous vide step ranged from 2.71 to 7.98 , with a median of $4.99 \log _{10}$ reductions. This variance was most likely due to improper positioning in the water bath, which prevented proper circulation. This occurred with a only 7 bags 
in the water bath, which is considerably less than what is commonly used.

Start Temperature Variation: Although the breasts were all cooled in the same manner, their internal temperatures varied. However, during the sous vide step a low start temperature did not always suggest a low $\log _{10}$ reduction, or vice versa. For example, sample 17 started at $8^{\circ} \mathrm{C}$, and achieved a $3.15 \log _{10}$ reduction, whereas sample 2 started at $1{ }^{\circ} \mathrm{C}$ and achieved a 6.12 $\log _{10}$ reduction. Therefore, it did not seem to significantly impact the results, but should be considered.

Variances in Searing: Variances occurred in the searing step were most likely due to wait times before the sear.

\section{DISCUSSION}

Safety of Sous Vide Recipes: There are many pathogens associated with duck breast, including Salmonella, Listeria, Yersina, Campylobacter and the Avian Flu $(1,7,8)$; therefore, it is important to achieve the required $7.0 \log _{10}$ reduction that the CFIA recommends for poultry (14).

A process that achieves adequate $\log _{10}$ reductions is referred to as "sous vide pasteurization (SVP)" (11, p3). If the required $\log _{10}$ reductions are not achieved the food must be processed to either reach the proper reduction or an internal temperature of $74^{\circ} \mathrm{C}$ (11). To ensure adequate processing, it is recommended to adhere to the BCCDC's Guidelines for Restaurant Sous Vide Cooking Safety in British Columbia, which are consistent with other guidelines and supported by microbiological studies $(15,16,17,11,18)$.

Studies on the safety of common sous vide recipes are limited. Studies done by Li and Do demonstrated that sous vide recipes for chicken and salmon did not meet the guidelines nor did they achieve sous vide pasteurization $(20,21)$. These studies did not assess the $\log _{10}$ reductions achieved. To better assess the recipe's safety, this study considered the $\log _{10}$ reductions achieved.

The results of this experiment concluded that the sous vide step did not achieve a 7.0 $\log _{10}$ reduction. However, once the duck breast was subjected to a final sear and rest period, the $\log _{10}$ reductions achieved were not significantly different from $7.0 \log _{10}$ reductions. Yet, due to a lack of normality, one cannot confidently say that the $7.0 \log _{10}$ reduction was achieved. However, the 7.0 $\log _{10}$ reduction is only a guideline, and many chefs fail to meet this guideline. Therefore, a recipe that achieves $\log _{10}$ reductions close to the guidelines may be considered an improvement. This recipe had a median $\log _{10}$ reduction of 7.08, and only 3 samples achieved less than a $5.0 \log _{10}$ reductions.

In terms of quality, the mean rating for colour was 4.3 out of 5 , and the mean texture rating was 4.4 out of 5 . High ratings were still achieved with a $7.0 \log _{10}$ reductions or higher. This suggests that sous vide can be both safe and of high quality.

\section{Significance of the Sear and Rest Step:} Chefs often claim that the searing helps achieve sous vide pasteurization or an internal temperature of $74^{\circ} \mathrm{C}$ (11). This was examined by Li and Do. Do examined one sous vide chicken breast, and noted that searing did achieve sous vide pasteurization (20). In contrast, Li examined 30 sous vide salmon and found that searing did not achieve sous vide pasteurization (21).

This experiment showed a wide variability in $\log _{10}$ reductions achieved by the sear and resting period. Therefore, the majority of $\log _{10}$ reductions must be achieved during the sous vide step. The sear and resting period may be used for small improvements. 


\section{RECOMMENDATIONS}

Based on the fact that the data lacked normally, one cannot confidently say that this recipe will consistently achieve $7.0 \log _{10}$ reductions. Therefore, it is not recommended from a public health point of view.

It is important that Environmental Health Officers (EHOs) familiarize themselves with the BCCDC's guidelines for sous vide (11). In order to prove a recipe is safe, one must show it matches the guidelines, reaches an internal temperature of $74^{\circ} \mathrm{C}$, or achieve the required $\log _{10}$ reductions. This may require the expertise of a Process Authority.

EHOs should also ensure Food Safety Plans are readily accessible with clearly outlined critical control points. They should also ensure operators are maintaining adequate temperature and calibration logbooks (21). In addition, Sanitation Plans should be in place to avoid contamination. EHO's should also ensure vacuum packed bags are fully submerged and arranged to allow proper circulation; properly sealed bags should not float (11). EHOs should also ensure that sous vide is stored at $3.3^{\circ} \mathrm{C}$ for no longer than 7 days to prevent the growth of Clostridium botulinum $(11,23)$.

Resources the EHOs can use include the BCCDC's guidelines, and the tools provided by the North American Meat Institute to calculate $\log _{10}$ reductions $(11,22)$.

\section{FUTURE RESEARCH SUGGESTIONS}

It is recommended to repeated this study with a larger sample size, and address any of the limitations discussed in this article. Future studies may also examine the $\log _{10}$ reductions achieved for duck breast prepared using the sear method, without sous vide. This is also a recipe of concern addressed by the BCCDC (1).

\section{CONCLUSION}

The data showed that duck breasts prepared for 80 minutes at $58^{\circ} \mathrm{C}$ sous vide step did not achieve $7.0 \log _{10}$ reductions. When the breasts were subjected to a 4 minute $200^{\circ} \mathrm{C}$ sear, as well as a 4 minute rest there was no statistical difference between the $\log _{10}$ reductions reached and $7.0 \log _{10}$ reductions. However, due to a wide variability in results, lack of normality one cannot confidently claim that the breasts achieved $7.0 \log _{10}$ reductions. The median $\log _{10}$ reductions provided by the sear step alone were 0.43 and the resting period provided 0.35 ; these results were highly variable (24). Therefore, it is recommended to use the sous vide step to achieve the majority of the $\log _{10}$ reductions, and only use the sear and rest for small increases. The breasts that achieved $7.0 \log _{10}$ reductions or higher generally had a rating of at least 4 out of 5 for colour and texture; this suggests that sous vide can be safe and of high quality.

\section{ACKNOWLEDGEMENTS}

The author would like to thank Helen Heacock and Fred Shaw from BCIT for providing the equipment, advice, and guidance. In addition, the author would like to thank Lorraine McIntyre and Pablo RomeroBarrios from BCCDC for providing the support, guidance, and assistance. Also, the author would like to thank Chef Tobias MacDonald from Vancouver Community Collage for providing the personnel, kitchen space, and equipment; as well as Chef Laura Dawe and the students for their assistance.

\section{COMPETING INTERESTS}

The authors declare that there are no competing interests. 


\section{REFERNCES}

The full length research paper for this article can be found in the BCIT Library Archive.

1. BC Centre for Disease Control Environmental Health Services. Sous vide style cooking of duck breast [Internet]. Vancouver: BC Centre for Disease Control; 2015 [cited 2015 Oct 1].

Available from:

http://www.bccdc.ca/NR/rdonlyres/1692F859-

D7A8-4B19-

8841C8418DEF412C/0/SVGuidelines_FinalforW eb.pdf

2. Hasheider P. The complete book of butchering, smoking, curing, and sausage making: how to harvest your livestock \& wild game [Internet]. China: Voyageur Press; 1951 [cited 2015 Oct 5]. 124 p. Available from Google Books:

https://books.google.ca/books?id=gHdcPexMP7 gC\&pg=PA124\&lpg=PA124\&dq=paraffin $+w a x+b$ ath+temperature,+feather+removal\&source $=b \mid$ \&ots=mGZJZB6IIc\&sig=uBtlk_vCbeEew8JA1G94r YGY5Y8\&hl=en\&sa=X\&ved =0CCcQ6AEwAmoVC hMI-O-

M4PrCyAIVkJmICh02Iwyr\#v=onepage\&q=paraffi n\%20wax\%20bath\%20temperature\%2C\%20feat her\%20removal\&f=false

3. Canadian Food Inspection System Implementation Group. Food retail and food services code [Internet]. Michigan: NSF International; 2004 [cited 2015 Oct 2]. Available from

http://foodsafe.ca/resources/Food_Services_Co de2004.pdf

4. Health Canada. . Safe internal cooking temperatures [Internet]. Ottawa: Health Canada; [date unknown] [updated 2015] [cited 2015 Oct 4]. Available from:

http://healthycanadians.gc.ca/eatingnutrition/healthy-eating-saine- alimentation/safety-salubrite/tips-

conseils/cook-temperatures-cuisson-eng.php

5. U.S. Food and Drug Administration. Safe food handling: What you need to know [Internet]. New Hampshire: U.S. Food and Drug Administration; [date unknown] [updated 2015] [cited 2015 Oct 4]. Available from:

http://www.fda.gov/food/foodborneillnesscont aminants/buystoreservesafefood/ucm255180.h tm

6. Government of Canada. Poultry safety [Internet]. [Place unknown]: Government of Canada; [date unknown] [updated 2015] [cited 2015 Oct 2]; Available from:

http://healthycanadians.gc.ca/eatingnutrition/safety-salubrite/turkey-dinde-eng.php

7. Jamali H, Radmehr B, Ismail S. Prevalence and antimicrobial resistance of Listeria, Salmonella, and Yersinia species isolates in ducks and geese. Poult Sci [Internet]. 2014 [cited October 3, 2015]; 93 (4): 1023-30. Available from: http://ps.oxfordjournals.org/content/93/4/102 3.full.pdf+html

8. Wei B, Cha S, Kang M, Roh J, Seo H, Yoon, R, et al. Antimicrobial susceptibility profiles and molecular typing of Campylobacter jejuni and Campylobacter coli isolates from ducks in South Korea. Appl Environ Microbiol [Internet]. 2014 [cited October 2, 2015]; 80(24): 7604-10

9. Rolánd M, Antequera T, Martín A, Mayoral Al, Ruiz J. Effect of different temperature-time combinations on physiochemical, microbiological, textural and structural features of sous-vide cooked lamb loins. Meat Sci. 2013 Mar; 93(3): 572-78.

10. Baldwin DE. Sous vide cooking: A review. Inter Journal Gastro Food Sci [Internet]. 2012 [cited October 5 2015]; 1 (1); 15-30. Available from: http://www.sciencedirect.com/science/article/ pii/S1878450X11000035 
11. BC Centre for Disease Control

Environmental Health Services and the BC Sous Vide Working Group. Guidelines for restaurant sous vide cooking safety in British Columbia [Internet]. Vancouver: BC Centre for Disease Control; 2014 [cited 2015 Oct 1]. Available from: http://www.bccdc.ca/resourcegallery/Documents/Guidelines\%20and\%20Form s/Guidelines\%20and\%20Manuals/EH/FPS/Food /SVGuidelines_FinalforWeb.pdf

12. Shellekens, M. New research issues in sousvide cooking. Trends Food Sci Technol. 1996 Aug; 7(8): 256-62.

13. Food Standards Agency. Safety of sous - vide foods: Feasibility of extending combase to describe the growth / survival / death response of bacterial foodborne pathogens between $40^{\circ} \mathrm{C}$ and $60^{\circ} \mathrm{C}$ [Internet]. United Kingdom: Food Standards Agency; 2012 [cited 2015 Oct 3]. Available from: https://www.food.gov.uk/sites/default/files/80 0-1-

1424_sous_vide_final_report_final_from_1FR_ 210912_after_spellcheck_and_formatting_0.pd $\mathrm{f}$

14. CFIA. Chapter 4 - meat processing controls and procedures [Internet]. [Publisher unknown]: Government of Canada; [date unknown] [updated 2014] [cited 2015 Oct 4]. Available from:

http://www.inspection.gc.ca/food/meat-andpoultry-products/manual-ofprocedures/chapter4/eng/1367622697439/1367622787568?chap= 6

15. Food and Drug Administration. FDA Food Code. College Park, MD: U.S. Department of Health and Human Services,; 2013 [cited 2014 January 6]; Available from: http://www.fda.gov/Food/GuidanceRegulatio n/RetailFoodProtection/FoodCode/ucm37427 5.htm
16. Food Safety Inspection Service [Internet]. Appendix A. Compliance Guidelines for Meeting Lethality Performance Standards For Certain Meat And Poultry Products. Nebraska: FSIS Technical Service Center; 1999 [cited January 11, 2016]. Available from: http://www.fsis.usda.gov/wps/wcm/connect/ 212e40b3-b59d-43aa-882ee5431ea7035f/95033F-a.pdf?MOD=AJPERES

17. United States Department of Agriculture [Internet]. Draft Compliance Guidelines for Ready-to-Eat Meat and Poultry Products. [Place unknown]: United States Department of Agriculture; [date unknown] [cited January 9, 2016]. Available from: www.fsis.usda.gov/OPPDE/rdad/FRPubs/97013P/RTEGuide.pdf

18. Sindelar, JJ, Glass, KA, \& Hanson, RD [Internet]. Developing Validated TimeTemperature Thermal Processing Guidelines for Ready-To-Eat Deli Meat and Poultry Products. Wisconsin: American Meat Institute Foundation; 2013 [cited January 10, 2016]. Available from:

http://fsrio.nal.usda.gov/nal_web/fsrio/printres ults.php?ID=8317

19. World Health Organization. Botulism [Internet]. [Place unknown]: World Health Organization; 2010 [cited 2015 Oct 1]. Available from:

http://www.who.int/mediacentre/factsheets/fs 270/en/

20. Do, Nova. (2013). Sous vide chicken pasteurization temperature. British Columbia Institute of Technology.

21. Li, Rebecca. (2014). Do, Nova. (2013). Sous vide salmon pasteurization temperature. British Columbia Institute of Technology.

22. North American Meat Institute. Process lethality spreadsheet [Internet]. [Place unknown]: North American Meat Institute; [date unknown] [cited January 11, 2016]. Available from: 
http://www.namif.org/content/process-

lethality-spreadsheet

23. NCSS [Internet]. List of statistical

procedures. NCSS. [Place unknown]; 2015 [cited

on January 7, 2016]. Retrieved from:

http://www.ncss.com/
24.Excel 2010 [Internet]. Excel 2010 tutorials. Excel. [Place unknown]; 2013 [cited on January 7,2016]. Retrieved from: http://www.excel2010.com/ 